\title{
Life cycle costing: evaluating its use in UK practice
}

\begin{abstract}
Purpose - The aim of this paper is to establish the extent to which life cycle costing is used as an early stage project evaluation tool by practitioners in the UK construction industry. The use of this evaluation tool has long been advocated by academics as a means of ensuring best value rather than lowest cost is a driver for business decisions related to potential built environment projects. Therefore there is a need to appraise its current uptake levels amongst built environment professionals and assess whether there are any barriers affecting its use in UK practice.

Design/methodology/approach - Using a mixed methods approach, the authors present the findings from a survey of construction professionals located in the UK and the results from a series of follow up semi structured interviews designed to further explore the factors found to affect the use of life cycle costing in practice.

Findings The study shows that life cycle costing is still not widely used by built environment professionals in the UK. The greatest inhibitor on the take up of the tool is the need of clients to budget on short term horizons. Other factors such as a lack awareness of the tool by practitioners and clients, unreliability of data into the long term and the overriding need for commercially driven projects to achieve maximum return on investment continue to inhibit the widespread adoption of life cycle costing as an early stage project evaluation tool. These findings have implications for the capability of the UK construction industry to deliver on its commitment to enhance the sustainability of the built environment.
\end{abstract}

Originality/value - The paper offers insights into the current use of life cycle costing and the factors affecting its use in the UK.

Keywords Life cycle costing, UK, usage, barriers to use

Paper type - Research paper

\section{Introduction}

The drive to work collaboratively and deliver best value rather than lowest cost for clients and other stakeholders involved in the development of built environment assets in the UK is now well established. Newer forms of project procurement tie the design, production and operation phases of the built environment project together, often within the remit of single organisations. As a result it would be expected that relevant built environment professionals need to be involved in delivering early stage project cost advice by making use of evaluative tools such as life cycle costing (LCC). Such a tool enables a better assessment of the long term implication of options related to the proposed building project's life cycle. LCC is a technique that seeks to evaluate the total design life costs of components or materials that are proposed to be part of a building project's design. It is asserted that the use of this approach to the formulation of early stage building project price advice would enable better financial decisions to be made in relation to the long term design life of the proposed asset. Kelly and Hunter (2009) suggest that the use of LCC has the ability to enhance a proposed building project's sustainability credentials by considering issues related to energy use and maintenance costs of different design alternatives. It is asserted generally that the use of such an early stage project evaluation tool would allow more informed cost advice to be generated than the early stage project cost advice currently generated that is based on a conventional initial capital cost basis.

Given this context the aim of this study was to establish the extent to which LCC is used as an early stage project evaluation tool by practitioners in the UK construction 
industry. Previous work has suggested that UK based built environment professionals have been slow to adopt LCC as a core tool for early stage project evaluation (Fortune and Cox 2005) so there is also a need to appraise whether there are any barriers to its use in UK practice. This paper is structured to consider firstly the background of previous work related to this topic so as to frame the problem in its context and then to determine an appropriate research approach. The results from the quantitative and qualitative phases of data collection together with a discussion of their implications are then presented

\section{Background}

Wolstenholme (2009) asserts that there is a need for industry to have a greater appreciation that better value, rather than lowest price, must be the focus for the early stage project evaluation of proposed built environment projects. A key tool in the ascertainment of future costs in-use of built environment assets is the use of LCC. Kirk and Dell'Isola (2003) assert that LCC is an approach to early stage building project evaluation that seeks to determine total expenditure on a project by analysing all materials, components, energy and other associated costs including maintenance costs throughout the design life of a proposed building project. In addition, one of the key aspects of performing a LCC analysis is the discounting of future costs to present value; this allows design option comparisons to be made on a level playing field (Cole and Sterner, 2000). Kelly and Hunter (2009) indicate that LCC can be used to predict 'cash flow of an asset' for budgeting, cost planning, tendering and cost reconciliation purposes. In addition LCC can also be used to facilitate design option appraisal studies and to assess present and likely future maintenance costs.

The benefits of using LCC are now appreciated by the stakeholders involved in the procurement of construction projects. Treasury Guidance (2003) updated in 2011, calls for value for money assessments of public projects to be executed through the use of LCC so as to ensure that the finished built environment project met the requirements of the projects' end-users. Similarly the requirement for the assessment of whole life costs is central to the early stage evaluation of National Health Service (NHS) facilities through it's procure 21 model. The use of LCC is advantageous for client organisations who intend to have a long term involvement with their built environment asset. These sentiments are corroborated in the work of Opoku (2013) who suggests such long term involvement with a building, together with a clear desire on behalf of the client to optimise ownership costs over the whole life of the asset can be seen as the primary drivers for commissioning life-cycle cost studies. However, these benefits are not restricted to client organisations. Kirkham et al (2004) suggested the nature of risk and the long-term financial implications of design decisions made by contractors as part of private finance initiatives and publicprivate partnerships mean the application of life cycle costing is becoming increasingly popular. Indeed the techniques usefulness in this regard is further espoused in the work of Swaffield and McDonald (2008) and Meng and Harshaw (2013) who acknowledge that despite the practical difficulties associated with implementation, life costing continues to be an important tool for ensuring the long term financial success of such schemes.

In terms of sustainability, it can be seen that the use of LCC can help to evaluate, at an early project stage, the environmental / economic aspects of a proposed building project design (Caplehorn, 2012). Whilst acknowledging that the majority of construction professionals are now actively promoting LCC as a decision tool for the evaluation of environmental sustainability. Gluch and Baumann (2004) Davis Langdon (2007) and Tsai et al, (2014) suggest that due to the tools financial focus 
such appraisals are often limited to the consideration of buildings energy usage. Given such profound limitations, Haapio and Viitaniemi (2008) and Ding (2008) question the usability of LCC as sustainability based tool, suggesting the financial focus of tools such as LCC could limit the validity of the sustainability evaluation produced. However, Barganca et al (2010) points out that when used alongside other sustainability evaluation tools, LCC plays an important role in the evaluation of potential project strategies. Schau et al (2011) concur with Barganca et al's opinion, contending the use of financial appraisal tools such as LCC within the overall decision environment allows the profitability of environmentally adapted choices to be fully considered thereby ensuring value for money is secured for the client (Liapis et al, 2014). Such benefits of LCC were illustrated in Aye et al's (2000) detailed appraisal of an environmentally designed, ecologically sustainable commercial office building in Australia where life cycle cost models were developed for both the building's energy performance and other environmental drivers as part of the justification for the selection of a more sustainable design solution. Yet despite of the possibilities relating to LCC, Brandon and Lombardi (2011, p.24) make clear that there are no shortage of reports and models of sustainability and how it should be inculcated into the processes associated with the production of built environment assets. However, they also assert that there remains a need for a framework that addresses social, economic and environmental aspects of sustainability to be developed that is multi layered and multi functional in its nature. Such a framework would assist in the early stage evaluation of potential building projects by informing stakeholders on the sustainability of their business decisions.

However, surveys of industry practice by Sterner (2000), Assaf et al (2002), Fortune and Cox (2005), Olubodun et al (2010) and again by Opoku (2013) indicate that the use of LCC as an aid for the early stage evaluation of proposed building projects is the practice of only a minority of practitioners. The identification of factors causing this gap between academe and practice is at the core of this study. Previous work by Kishk (2004), Kishk et al (2006) and Wu et al (2006) identifies the quality of the data available to execute the analysis of a potential building project's initial costs, future operating and maintenance costs, life cycles and discount and inflation rates as a critical issue affecting the use of LCC in practice. The problems associated with accessing reliable data is discussed within the work of Clift and Bourke, (1999), Cole and Sterner (2000) and Kirkham (2005) who proposed the formation of a forum similar to the approach advocated by Kishk et al (2003) which would allow the exchange of data and feedback. Despite the plausibility of this proposal, research undertaken by Davis Langdon (2007) for the European Commission revealed little interest amongst consultancy practices for the development of such a forum. Rising concerns that the collection and possession of such data maybe seen as 'commercially sensitive' and therefore not something to be openly shared. Kirkham's (2005) second suggestion that this forum would also act as a platform for agreeing a standard methodology for LCC analysis however, received far more support with Davis Langdon (2007) confirming a CEEC working group had been formed in 2007 with the aim of normalising life cycle costing methodologies across Europe.

Olubodun et al. (2010) found that the factors limiting the wider use of LCC were, a lack of understanding of the technique and its benefits as well as the need for a standardised method of application. However, there appears to be a lack of agreement on this issue as work by Perera et al.(2009) maintained that there were sufficient tools and guidance available on LCC and the development of more tools should be avoided in favour of dedicated training and the production of case studies outlining the different approaches to LCC. It is suspected that the increase in the use of Private Finance Initiatives (PFI) for the procurement of formerly publicly funded infrastructure projects will have resulted in an increased use of LCC as a tool for 
early stage project evaluation. The BS ISO 15686-5 (2008) standard for LCC was developed so that practitioners had a clear methodology to follow in order to help them increase the use of LCC in practice. In addition this standard also aimed at providing a framework for consistent LCC predictions and performance assessment of proposed projects. The take up and use of this standard is suspected as being a key development in the move of practitioners to the assessment of value rather than initial cost in the early stage evaluation of proposed built environment projects.

Bull (1993) identified the somewhat fragmented nature of the construction industry would be a key inhibitor to an increase in the uptake of LCC. The argument put forward by Bull (1993) implies that a lack of joined up thinking regarding the overall construction process would restrict its application. Each component of the construction process, whether planning, building or maintaining, is considered separately and this approach offers a complete contrast to the philosophy of LCC. In addition Cole and Sterner (2000) explain that bureaucratic structures affecting public sector client organisations have also severely restricted the use LCC analysis on their projects. Cole and Sterner (2000) assert that the way public funds are divided between capital spend and ongoing revenue budgets ensure that decisions are made in isolation from each other and not in accordance with the suggested LCC framework. These sentiments are further alluded to by both Perera et al.(2009) and Williamson et al (2010) who assert widespread reforms of public expenditure are required to allow LCC to be better incorporated within public procurement budgeting.

The literature reviewed above indicates that LCC is a potentially useful tool for use in the early stage evaluation of proposed built environment projects. It is clear that its use would contribute to the industry's achievement of more sustainable practices. However, evidence suggests that its use in practice is limited and largely restricted to the public sector. Also the available literature indicated that inhibitors to increasing the use of the tool in practice included, reliability of data and the lack of a standardised approach. As a result this study resolved to appraise the current uptake levels of LCC amongst built environment professionals and identify the significant barriers to its use in UK practice.

\section{Research Approach}

Researchers have long debated the relative value of qualitative and quantitative inquiry (Patton, 1990). Qualitative research uses a naturalistic approach that seeks to understand phenomena in context-specific settings whereas quantitative research uses deductive methods to test hypothetical generalisations. Each represents a fundamentally different inquiry paradigm, with research actions based on the underpinning philosophical assumptions. Yet despite the philosophical debates of the 1990s (Dainty, 2008) construction management research continues to reside in an arguably scientific epistemology. Yet, the majority of the problems researched by academe tend to be extracted from the realities of industry practice. This methodological paradox led Waddock and Spangler (2000) to espouse that if researchers are to be effective, they must see problems holistically, through lenses that are capable of simultaneously integrating multiple perspectives. This, Greenwood and Levin (2005:23) argue, is the crux of the real world; because the real world "does not issue problems in neat disciplinary packages" to which certain epistemologies can be neatly applied. Rather, researchers must move between epistemologies, in a way that enables the required research tools to be applied to the problem in order to identify a potential solution to it. 
As pragmatists do not see the world as an absolute unity, the pragmatic paradigm provides a strong philosophical underpinning for the design of pluralist research strategies (Teddie and Tashakkari, 2008) which are ultimately more suited to the real world situations encountered by researchers in the built environment (Fellows, 2010). As such, researchers working within this paradigm seek to apply a variety of methodologies for the collection and analysis of data rather than subscribing to one inquiry paradigm (Mertens, 2009). Thus, in pluralist designs, investigators use both quantitative and qualitative data as they work to provide the best understanding of a research problem (Johnson and Onwuegbuzie, 2004, Teddie and Tashakkari, 2008). Johnson and Christensen (2004) identify two dominant approaches to pluralistic research; the first is a multi-method, multi-phase design, in which the researcher uses one paradigm for one phase before changing to another for a further phase. The second approach is based on a mixed method approach, in which the researcher mixes both qualitative and quantitative approaches within a single phase of the research design. In designing the research approach for this study, it was clear that multiple disparate strands of activity were needed given the nature of the research problems identified above, together with the recommendations made at the conclusion of Opoku's (2013) earlier study, called for the adoption of a pluralistic research design in future studies to enhance our understanding of the contextual reasons driving the use of LCC in practice. It was therefore resolved to adopt a multi-method, multi-phase design research approach for this study.

As with previous studies examining industry practice (Sterner, 2000, Fortune and Cox, 2005, Olubodun et al, 2010, Opoku, 2013) the need to ascertain the extent of the use of LCC as an early stage project evaluation tool called for a quantitative research design that made use of a measuring instrument that allowed data to be collected from a large number of practitioners in the field. Both Creswell (2003) and Fellows and Liu (2008) indicated that the most appropriate data collection tool to use for this element of the study was a questionnaire survey. The design and use of such an instrument enabled the study not only to ascertain the extent of the use of the LCC techniques in practice but also to uncover the significance of factors alleged in the literature to be potential barriers limiting its use in practice. To ensure the validity of the research findings, the resultant data were then supplemented in terms of depth, richness and context by the adoption of a qualitative approach to data collection that used a series of semi structured follow-up interviews with practitioners in the field (Crotty,1998, Rubbins and Rubbins, 2005). Such interviews allowed the study to achieve its objective of uncovering the contextual reasons behind the adoption or non adoption of the LCC tool in practice. Whilst the adoption of a pluralistic research design ultimately allowed the researchers to use the strengths of each method to overcome, the inherent weaknesses of the others thus ensuring the validity and reliability of the results (Fellows and Liu, 2008).

Following the piloting of the questionnaire it was resolved to develop a random sample of survey participants by using Building Magazine's published lists of the top 100 cost consultants, architects, multi-disciplinary and contractors' organisations operating across the UK. As Opoku (2013:38) attests, Building's top 100 lists are sufficient in size to allow the whole population to be contacted within the time scale and cost limitations faced by the majority of researchers. A stratified sample of 250 organisations was systematically selected from the above population. The adoption of stratified random sampling allowed the researchers more control over the eventual sample to ensure it reflected the makeup of the overall population whilst also minimising the possibility by bias by ensuring every item of the population had an equal probability of being selected (Sapsford 2007). The electronic survey was distributed via email and was administered in a single phase. The survey achieved a $20 \%$ response rate. The survey responses were then augmented with a small 
number $(4 \mathrm{Nr})$ in-depth semi structured interviews with experienced practitioners drawn from each of the principal types of respondent organisations indicated above.

\section{Findings and Discussion}

Respondents to the survey, shown in figure 1, were drawn from quantity surveyors $(47 \%)$, architects (6\%), project managers (14\%) engineers $(8 \%)$ and others $(25 \%)$ situated in either consultancies (53\%) or in contracting organisations (47\%). The survey asked respondents to indicate their knowledge of LCC and $41 \%$ stated that they were either 'knowledgeable' or 'experienced' in its use. Only $10 \%$ of respondents indicated that they were 'not familiar' with LCC. Despite a small survey response $(n=49)$, the respondents are drawn from across the construction industry, advising both public and private sector clients. Making the outcome of the survey a reasonable reflection of what is happening in practice. This result shows that there may still be issues or factors that have an effect on the actual use of the LCC tool in practice.

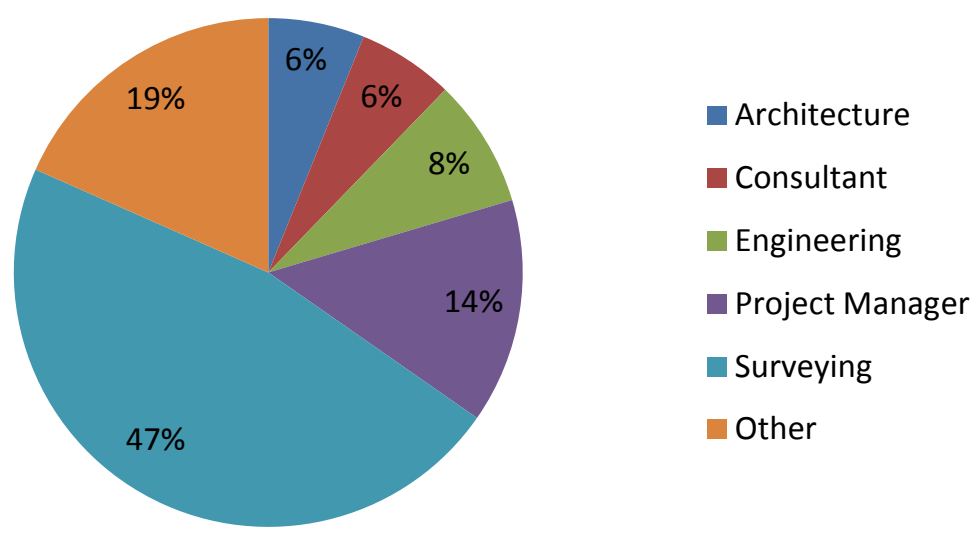

Figure 1 - Respondents Profile

The type of project is one issue that is thought to affect the use of LCC in practice. Table 1 shows the survey results and it can be seen that projects classified as being related to healthcare are the most likely type to be subjected to a LCC analysis. Of the 19 respondents some $47 \%$ indicated that they used LCC either 'often' or always' when evaluating this type of potential projects. This contrasts with the $8 \%$ and $11 \%$ of respondents who indicated that they used LCC either 'often' or 'always' when considering the early stage evaluation of industrial or commercial types of projects. Such a variation in results seems to indicate the differing time horizons that clients envisage being involved with health and commercial / industrial types of projects. Of more concern is the result showing that only $29 \%$ of respondents to the survey made use of LCC either 'often' or 'always' when considering the evaluation of education types of projects. It would be expected that clients for such projects would have a much longer time frame for engagement than clients of commercial / industrial projects. Table 1 also shows that the category 'rarely' used was the highest response rate for all types of projects in terms of using LCC as a tool for the early stage evaluation of all types of building projects. 


\begin{tabular}{|c|c|c|c|c|c|}
\hline Project Categories & Rarely(\%) & Sometimes(\%) & Often(\%) & Always(\%) & $\begin{array}{c}\text { Response } \\
\text { Count }\end{array}$ \\
\hline Housing & 55 & 9 & 27 & 9 & 11 \\
\hline Health & 48 & 5 & 26 & 21 & 19 \\
\hline Education & 57 & 14 & 7 & 22 & 14 \\
\hline Industrial & 78 & 11 & 11 & 0 & 9 \\
\hline Commercial & 77 & 15 & 8 & 0 & 13 \\
\hline Highway infrastructure & 50 & 13 & 25 & 12 & 8 \\
\hline \multirow[t]{2}{*}{ Other (Unclassified) } & 22 & 22 & 33 & 22 & 9 \\
\hline & & & $\begin{array}{c}\text { answ } \\
\text { skip }\end{array}$ & $\begin{array}{l}\text { red question } \\
\text { ed question }\end{array}$ & $\begin{array}{r}44 \\
5\end{array}$ \\
\hline
\end{tabular}

The survey required respondents to provide an indication of who typically initiates the need for a LCC analysis and figure 2 provides a summary of the results. Respondents clearly feel that the responsibility for the initiation of a LCC analysis lies with the client as 40 participants selected this option. This was followed by the cost advisor with 19 respondents selecting this answer. Figure 2 shows that consultants continue to offer a mainly reactive service to their clients in terms of using LCC as a tool to evaluate the long term cost implications of their potential building projects.

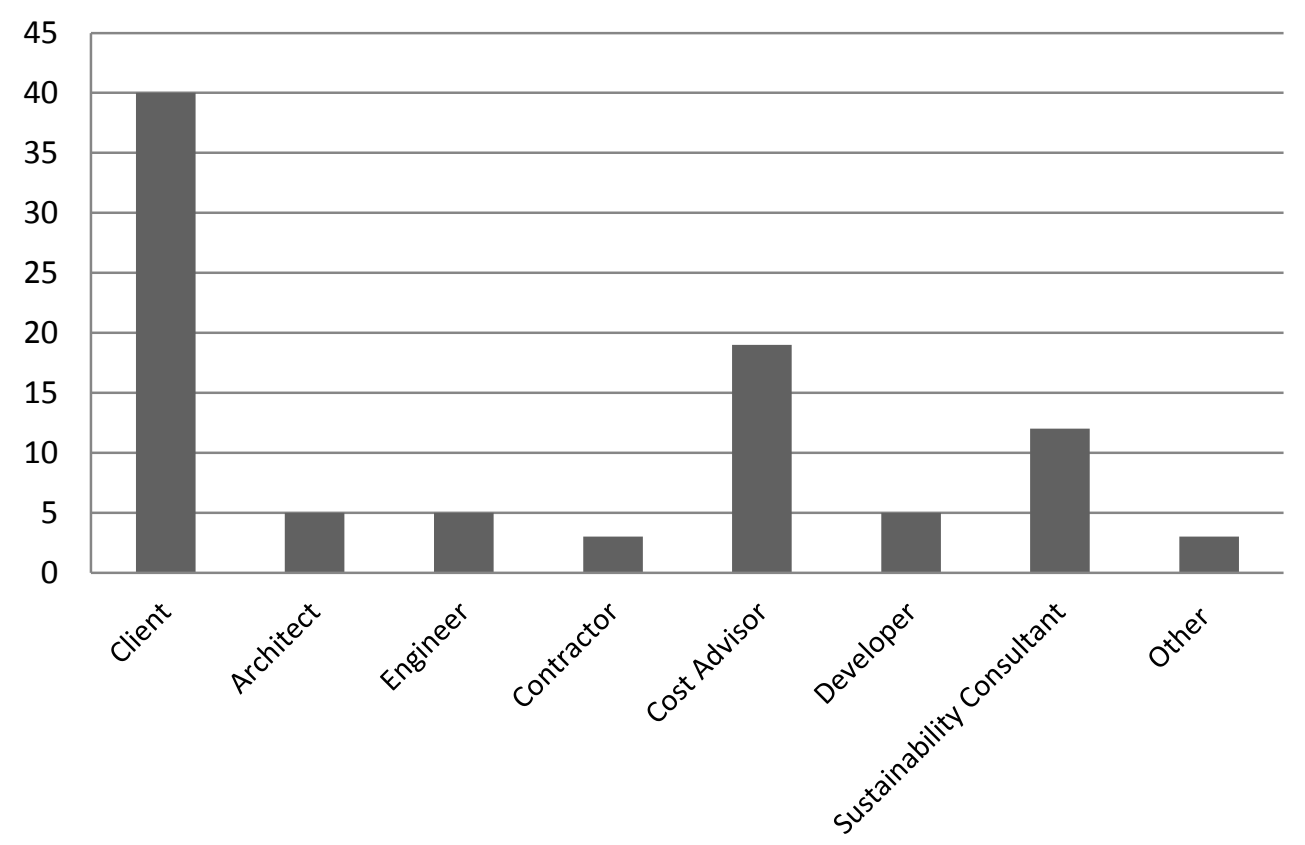

Figure 2 - Responsibility for Initiating LCC

Survey respondents were also asked to select the factors which had been suggested in literature as having the potential to inhibit more frequent use of LCC. The results to this question can be found in figure 3 . The results indicate that the key factor in limiting the increased use of LCC was the client's short term budget horizons with 28 participants selecting this option, equating to just over half $(57 \%)$ of the respondents. The next most frequently selected option was a lack of awareness of the benefits with 21 respondents selecting this factor, followed by a lack of client interest with 14 selections. Importantly, two of the least selected options (with 8 responses each) were a lack of reliable data and a lack of standardised approach. Each of these 
factors have been cited as barriers to the use of LCC within the literature reviewed above however the survey has found this not to be the case.

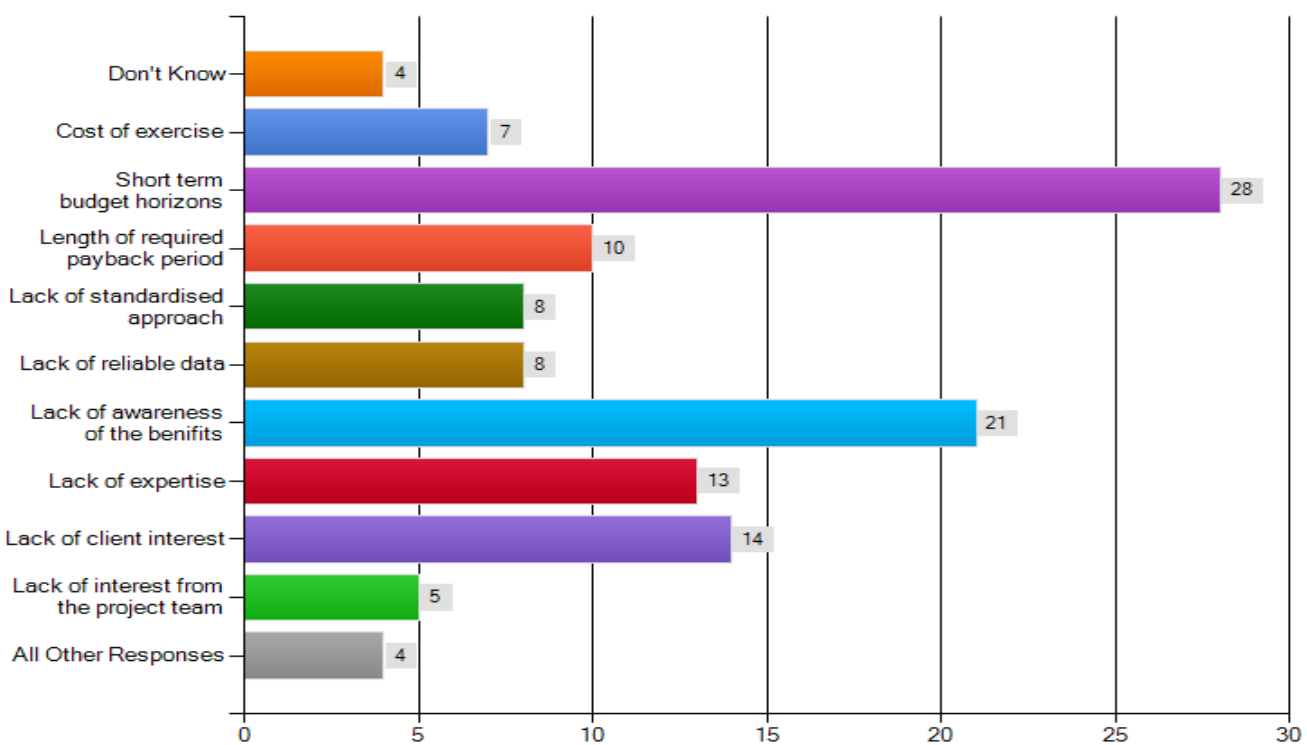

Figure 3 - Factors that Limit the Uptake of Life Cycle Costing

The survey gathered data to allow an assessment of the use of ISO 15686-5 Standardised Method of LCC to be established. Respondents of the survey were asked to state if they were aware of the ISO 15686-5 and the results are detailed below in figure 4 . The vast majority of respondents (87.2\%) were not aware of the ISO standard framework for LCC. When consideration is given to the fact that over two thirds $(69 \%)$ of respondents identified themselves as being a member of a professional built environment organisation and therefore participating in regular CPD sessions, the level of unawareness is concerning. The survey results give a concern for the consistency of the LCC advice provided by practitioners that is provided to their clients.

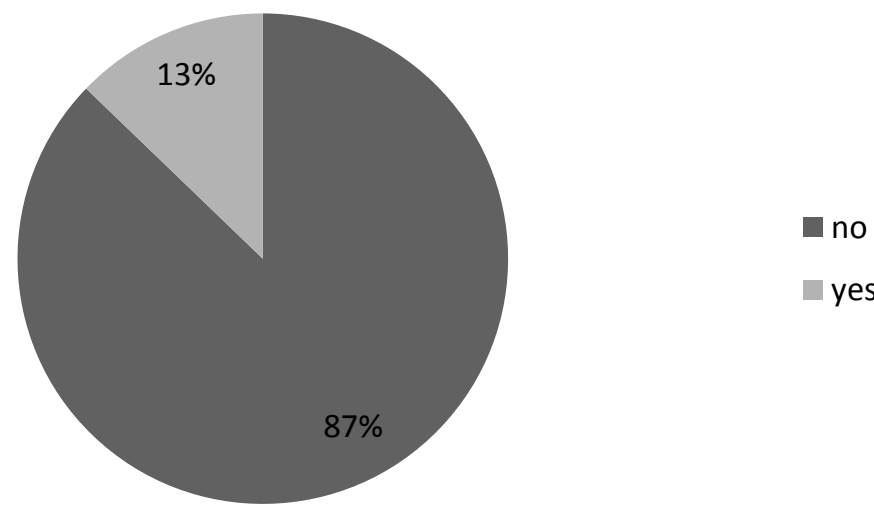

Figure 4 - Level of Awareness of ISO 15686-5

Given the survey results indicated above it was resolved to conduct some in-depth follow up interviews $(4 \mathrm{Nr}$ ) with a representative from each of the main organisational types included in the survey, namely, an architect (int 1), project manager (int 2), an engineer (int 3) and a quantity surveyor (int 4). The interviews were semi-structured 
in nature and used to explore the interviewees' experiences in terms of current uptake levels of LCC in general and factors that were perceived by them to be inhibiting the uptake of LCC in particular. This richer data adds context and depth to the results indicated above.

A key indicator of the validity and usefulness of LCC should surely be the levels of practical application and implementation within the construction industry. However, as Davis Langdon's (2007) comprehensive literature review revealed, this is an area where there are many contradictory views. Kirkham (2005) suggested the application of LCC within the construction industry had grown significantly following the introduction of long life procurement models such as PFI and PF2 (Kirkham et al, 2004). A view reinforced in the later work of Swaffield and McDonald (2008), Olubodun et al (2010) and Meng and Harshaw (2013). Yet surveys of industry practice undertaken by Bakis et al (2003) and Fortune and Cox (2005) countered this argument, suggesting that despite the growing importance of LCC as a risk management and sustainability appraisal tool, there remained limited application of the technique in practice. As a result of this confusion, the first strand of exploration related to current levels of LCC usage in practice, the majority of respondents to the questionnaire instrument had suggested LCC was rarely used in practice, confirming the earlier assertions made in the literature.

In terms of the actual usage of LCC in practice the following comment from int. 3 \& 4 was typical, namely,

'we deal with design and build, traditional, PFI, and partnering contracts and I have yet to see a LCC exercise done at all in any form on any of them.'

The above statement clearly suggests that LCC is rarely considered and also indicates that in the practitioners' experience the potential project's procurement route has little or no influence on the use of LCC as an evaluative tool. This assessment was followed up by int. 3 who stated that 'they had no experience of additional spending at the beginning of a project in order to generate long term cost savings'. Int. 2 also stated that LCC had rarely been given the attention it deserved, reporting that 'NHS projects had sometimes required a 'tokenistic' LCC assessment although it was now considered as a key KPl'. This theme was added to by int. 4 who said

'where a LCC study had been a procurement requirement say on a procure 21 project, then it was carried out very much as a box ticking exercise and stated that it had to be done to get it through the P21 process but it didn't influence the choice of any material or construction form or anything like that'.

The above comments support both the general findings of the survey in terms of the usage levels of LCC as well as the earlier work of both Bakis et al (2003) and Fortune and Cox (2005). In addition the comments call into question the claimed benefits of using LCC as a tool to aid the evaluation of sustainability in potential built environment building projects strongly advocated in Kelly and Hunter's (2009) Royal Institution of Chartered Surveyors funded work. The comments also indicate that even when LCC was carried out the findings did not necessarily influence the building's design or the generation of long term cost savings. These comments call for a further exploration of the factors that impact on the usage levels of LCC in practice.

A common barrier to the use of LCC in practice, identified through the questionnaire survey and confirmed by all the interviews has being the role that initial capital budget constraints and time horizons have on the ability of the built environment professionals to carry out and, or enforce the findings of a LCC study. Ints 1, 3, and 
4 all stated that capital cost was a key consideration when procuring a building. Int 4 went further to state that many problems exist in the way budgets are set and managed which seems to reduce the likelihood of LCC being utilised, or the findings of a study acted upon when he said,

'clients want to look at the overall cost of something over its life but at the end of the day the funds that are usually available are usually so tight that irrespective of whether something is going to cost more over the long term it normally means that the short term view has to prevail.'

Int. 3 also placed emphasis on a potential project's capital cost being too often the main consideration for building procurement and design, with less emphasis placed on attaining the building's overall LCC objectives when he commented 'there is a common theme here and it's that cost leads and not the long term objectives of the building'.'

In contrast to these views Int. 2 suggested that the current public sector financial restraints on capital spending, could potentially lead to an increase in the requirement to carry out LCC studies with the main reason being the lack of access to capital. Int. 2

'From my point of view we are entering into a new phase of how things are going to be run and LCC analysis is going to be crucial because there is not the access to capital in the way that has been previously.'

These findings add further validity to Perera et al (2009) and Williamson et al's (2010) urgent calls for the widespread reforms on public expenditure, whereby the traditional capital and revenue budgeting mechanisms favoured by public sector institutions will be abolished in favour of a single total expenditure budget, allowing public sector clients to place an enhanced focus on maximising through life value for money.

A further barrier appears to be that LCC studies are often considered too late on in the design process to be considered in relation to attaining the BREEAM credit or to have an impact on building design. Both ints. $1 \& 3$ state that this is often a factor limiting the use of LCC, with either the assessor being appointed too late or the client not realising the importance of an early LCC intervention with the following comment being typical,

'the LCC should have been done well before that and typically it hasn't and to be fair to the assessors don't get appointed till too late and you have missed the opportunity to do the LCC so it's a miss understanding at the beginning of what the client is trying to achieve.'

This issue was further emphasised by int. 1 who said that for LCC to be effective 'it should be implemented during RIBA stage $A / B$ '. The argument that LCC is most effective at this stage is based on the understanding that such an early intervention allows for 'optioneering' (option appraisals) to be carried out and design choices to be made based on their results. If this type of LCC analysis was carried out at a later RIBA design stage then int. 1 suggested that the results of the study would 'come too late to influence what would already be a fairly detailed design'. Int. 2 gave further support to these views suggesting that early intervention at the request of the client was essential in order to achieve the greatest impact in achieving lowest cost over the building's design life'.

Contrary to Opoku's (2013) observation that a significant number of private clients were sometimes asking for detailed Life-cycle cost models, the survey results indicated that type of project had an influence on the use of LCC and that it was more 
likely to be used on publicly procured construction projects, a finding supported by Olubodun et al's (2010) earlier survey. This can be accounted for by the increased legislation associated with public spending and the growth of the PFI where the contractor has a longer term interest in the buildings performance and running costs. However, Int 3's view of using LCC within the PFI procurement process was that the exercise was carried out as a means of minimising the risk to the contractor and not necessarily the provision of the lowest life cycle cost. Int. 3 stated,

'If you asked a PFI provider if they had a choice to pay extra for something that will last 60 years and his life cycle cost choice is simply to get to 25 years then that's his cheapest solution and from their point of view the LCC will have done its job'.

It appears that LCC is carried out in some capacity within the Procure 21 NHS method as alluded to by Int.4. However, int. 4 stated that the findings of the studies were not always be implemented and was also critical of the new procure $21+$ scheme as they felt the pain / gain share mechanism reduced the likelihood of extra capital spending. It appears that changes in the way this mechanism is administered, the contractor will not receive a gain share payment if costs increase even if they are proved to offer better long term value. Int. 4 also explained that the speed in which health care facilities develop often leads to obsolescence within shorter time frames than other buildings and as a result 'the wants and needs of the NHS trusts change'. Int. 3 argued that within privately procured construction projects there is no incentive to achieving lowest life cycle cost especially when taking the view of a developer. Int. 3 said that buildings with lower life cycle costs do not yet command higher rents or purchase values; therefore the developer would not necessarily achieve a return on their increased capital investment. It was felt that 'until extra capital spending could generate an increased return, developers will be reluctant to consider applying LCC philosophies'.

The survey reinforced found that lack of awareness of LCC and its potential benefits was a barrier to its use in practice and so this issue was explored with the interviewees. Int. 1 claimed that there was a lack of understanding amongst the design team regarding the considerations required when designing for lowest life cycle cost. For instance Int. 1 said,

'I don't know that many of my colleagues sit down and think right this building has got to be designed for 60 years what does that mean, does it mean I am designing for deconstruction, does it mean I am designing for re-use, does it mean I am designing for climate change adoption probably not'.

Int. 1 also stressed that it should be the consultant's obligation to advise the client to look to achieve a better value building and it was suggested that 'consultants, often through a lack of understanding, miss this opportunity'. Int. 3 backed up this view when he explained that the benefits of such a study far outweigh the cost of carrying it out and yet there appears to be an overall misunderstanding amongst colleagues about a building's long term objectives'.

Interestingly the interviewees placed more weight on other barriers to the use of LCC rather than the emphasis given to 'a lack of awareness or understanding of the technique itself' that was revealed as a major barrier in the survey. Fort instance Int. 4 explained that in their experience 'the amount of assumptions which are required to be made when carrying out a LCC can affect the level of accuracy it can achieve'. Int. 3 also conveyed fears regarding the accuracy of such a study explaining that when considering the maintenance of a building 'you can only go so far into a buildings life cycle before you are guessing'. Int 4 also pointed out that there was a potential for contradictions when a LCC analysis has taken place, particularly when administering 
a value engineering (VE) exercise to ensure the tender sum for a project is kept within its initial capital budget. For instance the following example was cited,

'So if you do a LCC on a lighting scheme that recommends more expensive fitting and over its life which will save you money due to lower maintenance etc. You will get a suggestion that value engineering the lighting is a good way to save $x$ amount of the initial outlay, and this will normally be the option taken particularly if the project is over budget.'

This statement also highlights once again the overriding impact short term budget constraints have on the ability of clients to increase capital spending even if long term savings can be illustrated. However, the data analysis presented above has identified that other factors continue to be barriers to the more widespread use of LCC in practice, namely project type and an unreliability of data related to long term cost implications of design options. Interestingly a lack of awareness of the technique itself was not given emphasis by the interviewees as an inhibiting factor affecting the use of LCC in practice. The analysis of the data revealed that none of the interviewees were aware of the existence of the BS-ISO15686-5 standard. This is a concern given that the standard was developed to advance a framework / standard method for LCC analysis and this together with the similar survey results (Sterner, 2000; Olubodun, 2010; Opoku, 2013) points to the need for continued CPD work in this area.

\section{Conclusions and recommendations}

The benefits of LCC are well documented and it is frequently cited as a means of achieving best value at the early stage evaluation of proposed built environment projects. However, the study found that LCC is rarely used across all sectors of the UK construction industry. Evidence showed that LCC is more likely to be used on publicly procured projects such as health care and education. Of the factors thought to inhibit the use of LCC as a tool for early stage project evaluation it was found that the prevailing climate of 'short termism' in terms of the budget horizons of clients was the major barrier to LCC not being in more general use. In addition it was found that there was still a gap in understanding and awareness of the benefits of a LCC approach to early stage project evaluation that inhibited clients from requesting such information from their built environment professionals. Factors such as unreliability of data and a lack of use of a standardised approach continue to affect the use of LCC in practice.

Given that the industry is committed to deliver sustainable built environment assets for its clients and other stakeholders it seems that there remains a gap between policy and practice in terms of the use of LCC as one of the UK construction industry's core early stage project evaluation tools. The effective early stage evaluation of the sustainability of proposed building projects also calls for built environment professionals to become more pro-active in the use of LCC as part of their normal service delivery to clients. In terms of academe this study points to the need for further underpinning work related to the general concepts of early stage sustainable benefit evaluation. In particular there is a need to establish a framework to add to the LCC tool in order for practitioners to better evaluate the potential social / economic as well as the environmental / economic benefits of proposed building projects that can currently be assessed through the use of LCC. 


\section{References}

Assaf, S.A., Al-Hammad, A., Jannadi, O.A. and Saad, S.A. (2002) Assessment of the problems of application of life cycle costing in construction projects. Cost Engineering Vol, 44 No 2 pp.17-22

Aye, L.,Bamford, N., Charters, B and Robinson, J. (2000) Environmentally sustainabl development: a life cycle costing approach for a commercial office building in Melbourne, Australia. Construction Management and Economics, Vol 18 pp.927-934.

Bakis, N., Kagiouglou, M., Aouad, G., Amaratunga, D., Kishk, M and Al-Hajj, A. (2003) An integrated environment for life cycle costing in construction. Proceedings of the CIB W78's 20 th International Conference on Construction IT, Construction IT bridging the distance. CIB Report 284, Waiheke Island, 23-25 April

Brandon P S and Lombardi P L (2011) Evaluating Sustainable Development, Blackwell-Wiley, Oxford, UK

British Standard Institution. (2008) BS ISO 15686-5: 2008 Buildings \& constructed assets - Service life planning - Part 5: Life cycle costing. London: BSI

Braganca, L., Mateus, R and Kokkari, H. (2010) Building Sustainability Assessment. Sustainability, Vol, 2 pp. 2010-2023.

Bull, W. (ed.) (1993) Life Cycle Costing for Construction. London: Blackie Academic \& Professional

Caplehorn, P. (2012) Whole Life Costing. A New Approach. Routledge: Abingdon, UK

Clift, M. and Bourke, K. (1999) Study on whole life costing. Report prepared for DETR, Feb 1999 Report Number CR 366/98

Cole, R. and Sterner, E. (2000) Reconciling theory and practice of life-cycle costing. Building Research \& Information, 28: 5, 368 - 375

Cresswell, J. (2003) Research Design: Qualitative and Quantitative Approach. London: Sage

Crotty M (1998) The Foundations of Social Research: Meaning and Perspectives in the Research Process, Sage Publications, London

Dainty, A. (2008) Methodological Pluralism in Construction Management Research.

In: Knight, A. and Ruddock, L. (ed) Advanced Research Methods in the Built

Environment. West Sussex: Wiley-Blackwell.

Davis Langdon (2007) Life cycle costing (LCC) as a contribution to sustainable construction: A common methodology - Final Report. London: Davis Langdon.

Ding, G.K.C. (2008) Sustainable Construction - The role of environmental assessment tools. Journal of Environmental Management, Vol. 86 pp.451-464

Fellows, R. (2010) Editorial: New Research paradigms in the built environment. Construction Innovation. Vol, 10 No 1, pp. 5-13.

Fellows, R. and Liu, A. (2008) Research Methods for Construction. West Sussex:

Wiley-Blackwell.

Fortune $\mathrm{C}$ and Cox $\mathrm{O}$ (2005) Current practices in building project contract price forecasting in the UK, Engineering Construction and Architectural Management, Vol $12 \mathrm{Nr} 5$ p. $446-457$

Gluch, P and Baumann, H. (2004) The life cycle costing (LCC) approach: a conceptual discussion of its usefulness for environmental decision making. Building and Environment, Vol, 39 pp.571-580.

Greenwood, D.J. and Levin, M. (2005) Reform of the social sciences and of universities through action research. In: Denzin, N,K and Lincoln, Y.S. (Eds) The Sage Handbook of Qualitative research, $3^{\text {rd }} \mathrm{Ed}$. London: Sage Publications Ltd. Haapio, A and Viitaniemi, P (2008) A critical review of building environmental assessment tools. Environmental Impact Assessment Review Vol.28 pp.469-482 
H.M. Treasury (2003) The Green Book. Appraisal and Evaluation in Central Government. London: The Stationary Office.

Johnson, B. and Christensen, L. (2004) Educational Research: Quantitative, Qualitative and Mixed Approaches. Research Edition. $2^{\text {nd }}$ Ed. New York: Allyn and Bacon.

Johnson, R.B. and Onwuegbuzie, A.B. (2004) Mixed Methods Research: A Research Paradigm Whose Time Has Come. Education \& Educational Research. Vol, 33 No 7 pp. 14-26.

Kelly, J and Hunter J (2009) Life Cycle Costing of Sustainable Design, RICS, London Kirk, S.J. and Dell'Isola, A,J. (2003) Life Cycle Costing for Facilities. New York: Reed Construction Data

Kirkham, R J, Alisa, M, Silva, A P d, Grindley, T and Brøndsted, J (2004) Rethinking whole life cycle cost based design decision-making. In: Khosrowshahi, F (Ed.), Proceedings 20th Annual ARCOM Conference, 1-3 September 2004, Edinburgh, UK. Association of Researchers in Construction Management, Vol. 1, 91-103.

Kirkham, R.J. (2005) Re-engineering the whole lie cycle costing process. Construction Management and Economics, 23: 1, 9 - 14

Kishk, M. (2004) Combining various facets of uncertainty in whole-life cost modelling. Construction Management and Economics, 22: 4, 429 - 435

Kishk, M, Al-Hajj, A., Pollock, R. andAouad, G. (2003) Effective feedback of wholelife data to the design process. Journal of Financial Management of Property and Construction. Vol. 8 No 2 pp.89-98.

Kishk, M., Laing, R. and Edge M. (2006) An extended whole-life application for the selection of hospital finishes. In: Boyd, D. (Ed) Procs $22^{\text {nd }}$ Annual ARCOM conference, 4-6 September 2006, Birmingham, UK, Association of Researchers in Construction Management, 719-728.

Liapis, K.J., Kantianis, D and Galanos, C.L. (2014) Commercial property whole-life costing and the taxation environment. Journal of Property Investment and Finance, Vol, 32 No 12014 pp. 56-77

Meng, X and Harshaw, F (2013) The application of whole life costing in PFI/PPP projects. In: Smith, S.D. and Ahiaga-Dagbui, D.D. (Ed.), Proceedings 29th Annual ARCOM Conference, 2-4 September 2013, Reading, UK. Association of Researchers in Construction Management, 769-778.

Mertens, D.M. (2009) Research methods in education and psychology: Integrating diversity with quantitative and qualitative approaches. $3^{\text {rd }}$ ed. London: Sage

Publications Ltd.

Olubodun, F., Kangwa, J., Oladapo, A., and Thompson, J. (2010) An appraisal of the level of application of life cycle costing within the construction industry in the UK. Structural Survey Vol, 28 No 42010 pp, 254-265

Opoku, A. (2013) The application of whole life costing in the UK construction industry: Benefits and Barriers. International Journal of Architecture, Engineering and Construction Vol, 2 No 12013 pp, 35-42

Patton, M.Q. (1990) Qualitative Evaluation and Research Methods. Newbury Park:

Sage.

Perera, O., Morton, B. and Perfrement, T. (2009) Life Cycle Costing in Sustainable Public Procurement: A Question of Value. International Institute for Sustainable Development: A white paper from IISD

Rubin, H. J., and Rubin, I. S. (2005). Qualitative Interviewing, the Art of Hearing Data. $2^{\text {nd }} \mathrm{Ed}$. London: Sage publications Itd.

Sapsford, R. (2007) Survey Research. 2nd Ed. London: Sage Publications

Schau, E.M., Traverso, M., Lehmann, A and Finkbeiner, M (2011) Life cycle costing in sustainability assessment - A case study of remanufactured alternators. Sustainability, Vol, 3 pp. $2268-2288$.

Sterner, E. (2000) Life-cycle costing and its use in the Swedish building sector. Building Research and Information Vol, 28 No 5/6 pp. 387-393 
Swaffield, L.M. and McDonald, A.M. (2008) The contractor's use of life cycle costing on PFI projects. Engineering, Construction and Architectural Management. Vol, 15 No 22008 pp. 132-148

Teddlie, C. and Tashakkori, A (2009) Foundations of Mixed Methods Research: Integrating Quantitative and Qualitative approaches in social and behavioural sciences. London: Sage Publications Ltd

Tsai, W., Yang, C., Chang, J and Lee, H. (2014) An activity-based costing decision model for life cycle assessment in green building projects. European Journal of Operational Research Vol. 228, pp.607-619.

Waddock, SA. Spangler, E. (2000) Action learning in leadership for change:

Partnership, pedagogy, and projects for responsible management development. In:

Sherman, E. and Torbert, W. (Eds.) Transforming social inquiry, transforming social action: New paradigms for crossing the theory/ practice divide in universities and communities. Boston: Kluwer.

Williamson, A., Williams, C and Gameson, R. (2010) The consideration of maintenance issues during the design process in the UK public sector. In: Egbu, C. (Ed) Procs 26 $6^{\text {th }}$ Annual ARCOM Conference, 6-8 September 2010, Leeds, UK, Association of Researchers in Construction Management, 1091-1100.

Wolstenholme, A (2009) Never waste a good crisis a review of Progress since Rethinking Construction and Thoughts for our Future, Sage Publications, London

Wu, S., Clements-Croome, D., Fairey, V., Albany, B., Sidhu, J., Desmond, D and Neale, K. (2006) Reliability in the whole life cycle of building systems Engineering Construction and Architectural Management Vol, 13 No 2 pp.136-153 